\title{
Hand hygiene as the basic method of reducing Clostridium difficile infections (CDI) in a hospital environment
}

\author{
Zofia Maria Kiersnowska ${ }^{1, A-D \oplus}$, Ewelina Lemiech-Mirowska ${ }^{1,2, B-C \oplus}$, Michał Michałkiewicz ${ }^{3, E-F} \oplus$, \\ Michał Marczak ${ }^{4, F} \odot$ \\ ${ }^{1}$ Project InterDoktorMen, Medical University of Lodz, Poland \\ ${ }^{2}$ Laboratory of Epidemiology, Military Institute of Hygiene and Epidemiology (WIHE), Warsaw, Poland \\ ${ }^{3}$ University of Technology, Institute of Environmental Engineering, Poznan, Poland \\ ${ }^{4}$ Department of Management and Logistics in Health Care, Medical University of Lodz, Poland \\ A - Research concept and design, B - Collection and/or assembly of data, C - Data analysis and interpretation, \\ $D$ - Writing the article, E-Critical revision of the article, F - Final approval of article
}

Kiersnowska ZM, Lemiech-Mirowska E, Michałkiewicz M, Marczak M. Hand hygiene as the basic method of reducing Clostridium difficile infections (CDI) in a hospital environment. Ann Agric Environ Med. 2021; 28(4): 535-540. doi: 10.26444/aaem/131121

\begin{abstract}
Introduction. Clostridium difficile spores, due to their ability to adapt to adverse conditions in a hospital environment, cause enormous difficulties associated with the effective decontamination of surfaces and equipment. Elimination of this pathogen is possible through effective implementation of the hand hygiene procedure by all hospital employees. Scientific research indicates that a properly adopted hand washing procedure reduces the risk of Clostridium difficile infection (CDI) by half.

Objective. The aim of the study was to indicate the sources of nosocomial infections, mainly Clostridium difficile infection, and methods to limit them, with particular attention paid to the proper hand hygiene of the medical staff, which plays a fundamental role in the transmission of infections between hospitalized patients.

Brief description of the state of knowledge. Epidemiological studies indicate that about a half of Healthcare Associated Infection (HAl) is caused by microbes that contaminate the hands of medical personnel. One of the main pathogens is Clostridium difficile, which in 2018 in Poland accounted for $41.52 \%$ of all detected outbreaks originating from the hospital environment. According to data from WHO,16 million people worldwide die from Healthcare Associated Infection every year, of which approximately $17 \%$ constitutes mortality among people infected with Clostridium difficile.

Conclusions. Non-compliance with hand hygiene among members of medical staff contributes to nosocomial infections which are a major cause of disease complications and deaths. Proper hand hygiene is a key measure for reducing this phenomenon. In every medical institution, especially in hospitals, and staff should be reminded about it and trained to perform the correct hand hygiene technique.
\end{abstract}

\section{Key words}

Clostridium difficile infection, hand hygiene, infection prophylaxis

\section{INTRODUCTION}

A powerful and effective weapon in the fight against Healthcare Associated Infections (HAI) is a rigorous adherence to the hand hygiene procedure that concerns both to the quality of patient and staff safety, and to good epidemiological practice. Hand washing is a standard activity, performed routinely and unconditionally before and after each contact with the patient, the patient's environment (e.g. devices, medical equipment), contaminated surfaces, before and after breaks in activities performed on the patient, contact with blood and other body fluids, and, among others, after going to the toilet or taking off gloves. This activity lies at the heart of hospital hygiene. Ignoring the rules of proper hand washing by medical professionals may lead to serious consequences for hospitalized patients, especially the elderly or those with reduced immunity [1]. HAI are one of the main causes of hospital adverse events [2]. Every year, 16

Address for correspondence: Zofia Maria Kiersnowska Project InterDoktorMen, Medical University, Lodz, Poland

E-mail: zofiakiersnowska.p@gmail.com

Received: 09.06.2020; accepted; 01.12.2020; first published: 04.01.2021 million people worldwide die from HAI, of which $17 \%$ is the mortality among people infected with Clostridium difficile [3]. Infection caused by this pathogen leads to significant deterioration of patients' health manifested by diarrhoea and dehydration. Along with the development of the disease, pathological changes in the intestine appear, signaling pseudomembranous colitis, which, if left untreated, can lead to death [4-6]. Due to the ability of $C$. difficile spores to adapt to adverse conditions in a hospital environment, they cause enormous difficulties associated with the effective decontamination of surfaces and equipment [7]. Elimination of this pathogen is possible through effective implementation of the hand hygiene procedure by all hospital employees.

Epidemiology of Clostridium difficile. Clostridium difficile is a Gram-positive anaerobic bacillus that has the ability to produce spores, i.e. microscopic reproductive units. Spore units naturally occur in water, soil, and hospital environments, and may also be present in the gastrointestinal tract in humans and animals [8]. In its spore form, the bacterium can survive under harsh conditions and against commonly used sterilization techniques. C. difficile spores are resistant 
to high temperatures, ultraviolet light, aggressive chemicals and antibiotics. Moreover, because spores are resistant to antibiotics, they can remain in the gastrointestinal tract and potentially contribute to disease relapses following treatment and eradication of vegetative $C$. difficile. Strains such as Ribotype 027 (especially its spores) spread more easily in the hospital environment because they are resistant to the hospital cleaning and disinfectants [6].

In the case of CDI (Clostridium difficile Infection) outbreaks or in wards with a persistently high incidence, hand hygiene should be preferably performed with soap and water rather than with alcohol-based products. Washing hands with soap and water is also recommended before and after any medical procedures performed on the patient in the case of direct contact with the faeces or an area highly contaminated with faecal flora (e.g. the perineal area). This is important because soap and water are more effective in removing spores.

In a hospital environment, $C$. difficile spores are primarily transmitted between patients via healthcare workers hands. Contaminated surfaces and utensils that are present in the hospital serve as a reservoir for this pathogen. Antibiotic therapy is the main risk factor for CDI, especially the one involving the use of broad-spectrum antibacterial drugs [9]. Another important factor is the age above 65 years. In Poland in 2018, patients over 65 accounted for $71.3 \%$ of all $C$. difficile-related infections [10]. An additional factor contributing to CDI is the length of the patient's stay in the hospital. The authors of the current study estimate that the occurrence of CDI in a patient increases with the duration of hospitalization even up to $50 \%$ for stays longer than 4 weeks $[6,8,11]$. Infections having $C$. difficile etiology pose a serious public health problem [12]. In 2018, in hospitals all over Poland, C. difficile was responsible for $41.52 \%$ of all detected epidemic outbreaks, which resulted in 11,592 cases of infection, in comparison to 4,738 cases in 2013 $[2,6,10,13]$. In most cases, the infected patients were over 75 years of age, and accounted for $48.4 \%$ of cases, whereas patients aged $65-74$ constituted $22.9 \%$ of those infected, with a slight prevalence of females in $15.2 \%$ [10]. One study has shown that the time of year is important for an increase in CDI incidence. In 2018, 4,999 patients were infected in the period January - April, which constituted $44.6 \%$ of all C. difficile infections, whereas in March the highest number of infections was $1,358-12.1 \%$ [10]. During the summer (June - August) there was a decrease in infections, which amounted to 2,431 in that period, whereas at the end of the year (October - December) 2,100 cases were attested [10].

Personnel's hands as a reservoir for Clostridium difficile spores. Numerous studies have shown that the hands of staff due to direct contact with the patient during diagnostic, therapeutic or nursing procedures are particularly exposed to pathogenic microorganisms [4, 12]. Approximately $3.9 \times 10^{4}$ to $4.6 \times 10^{6}$ different kinds of microorganisms can be found on the hands of medical personnel [7]. McFarland et al. [14] report that after direct contact with a patient with CDI, as many as $59 \%(\mathrm{~N}=35)$ of medical employees were found to have C. difficile spores. Moreover, it was demonstrated that C. difficile was found on the hands in $37 \%$ of cases, under rings in $20 \%$ of cases, and on fingertips in $37 \%$ of cases [14]. Others studies confirm that pathogens can survive on the hands of personnel from several to several dozen minutes after contamination $[15,16]$. When performing professional activities, the staff's hands come into contact not only with a patient infected with C. difficile, but also with other patients not infected with $C$. difficile and various types of surfaces and objects needed for work, where e.g. spores of the discussed anaerobic bacteria can be found. Therefore, the principles of hand hygiene should be applied before and after contact with each patient.

Most of thespores are transferred from hands to hands or from hands to surfaces, and their transmission, especially those staying temporarily, depends on their type, number, survival rate and location on the skin of the hands [17-19]. Otter et al. reported that the hands or gloves of medical staff who did not have direct contact with the patient with CDI, but only with the patient's room, were contaminated. In this study, C. difficile spores were detected in $50 \%$ of staff members ( $\mathrm{N}=30$ ), VRE (vancomycin-resistant Enterococcus) strains were detected in $52 \%$ of staff members $(\mathrm{N}=44)$, and MRSA (methicillin-resistant Staphylococcus aureus) were detected in $45 \%$ of staff members $(\mathrm{N}=50)$ [20]. The contamination of the hospital environment and the hands of medical workers are usually directly linked together; therefore, the hands of medical staff are an important vector for the transmission of multi-resistant pathogens $[4,12]$. With a single direct contact with a contaminated environment, from $4 \%-16 \%$ of the surface of the member of staff's hand is colonized (contaminated), while after the next 12 contacts, as much as $40 \%$ of the skin surface of the hand is colonized (Tab. 1) [18]. The survival rate of selected bacterial pathogens is presented in Table $1[4,17,18]$.

Table 1. Survivability of selected bacterial pathogens

\begin{tabular}{lcc}
\hline Pathogen & $\begin{array}{c}\text { Survival time in a } \\
\text { hospital environment }\end{array}$ & $\begin{array}{c}\% \text { share of contamination } \\
\text { of hands of staff }\end{array}$ \\
\hline Clostridium difficile (spores) & $>5$ months & $14 \%-59 \%$ \\
\hline Acinetobacter & 3 days - 11 months & $3 \%-15 \%$ \\
\hline Enterococcus with VRE & 5 days - $>46$ months & Unknown \\
\hline Pseudomonas & 6 hours -16 months & $1 \%-25 \%$ \\
\hline Enterococcus & 5 days -4 months & $>40 \%$ \\
\hline Klebsiella & 2 hours $->30$ months & Unknown \\
\hline Staphylococcus aureus & 7 days $->12$ months & Unknown \\
\hline
\end{tabular}

Clostridium difficile is able to survive up 5 months in a hospital environment, e.g. on the hospital floor, and over 5 weeks on medical equipment $[4,8,18]$. C. difficile spores exhibit high adhesion and their main living places are floors, toilets and sinks, door handles, medical equipment (monitors, ultrasound devices, drip stands, blood pressure meters), telephones, handles near patient beds and bed linen $[21,22]$. Removal of spores, despite their adhesive properties, is possible only with proper disinfection of hospital surfaces combined with compliance with hand hygiene procedures by medical staff. One study showed that $75.2 \%(\mathrm{~N}=101)$ of nursing staff believe that hand disinfection performed immediately prior to contact with the patient avoids colonizing the patient with hospital flora [23]. On the basis of this study, it can be concluded that the awareness among nursing staff is high, but at the same time the question can be posed whether awareness of the problem goes hand in hand with the practice? Undoubtedly, the hospital environment is a specific area of risk and understanding the factors threatening the stability of the processes affecting the safety of the patient is essential for the eradication of $C$. difficile. 
It is undeniable that the hospital environment has a huge impact on the transmission of multi-resistant pathogens via the hands of medical staff $[1,24,25]$. The hospital environment is a specific area in which it is possible to develop hospital infections during the diagnostic and therapeutic process. However, proper hand hygiene is a basic measure intended to limit the occurrence of this phenomenon. Epidemiological studies indicate that about a half of HAI is caused by microbes originating from the hospital environment that contaminate the hands of medical staff $[7,24]$.

Factors affecting hand hygiene compliance. Patient safety is the most important goal of maintaining high quality medical care, and achieving it requires the involvement of many people. The mere presence of various recommendations from organizations such as the World Health Organization (WHO) or Centers for Disease Control and Prevention (CDC), as well as procedures, laws, regulations, trainings, supervision or implementation of a new hand hygiene programme, will not have a positive impact on the reduction of HAI. This can only be achieved by the continuous, active participation and compliance by all medical staff and the higher organizational level [26-28]. Although the human factor is the main cause of HAI, in the health care system where a system should be created for preventing and combating hospital infections that would introduce systematic changes reflected in a decrease in the number of cases, and would eliminate bad hygiene habits, lack of internal motivation, resulting in the increase in awareness of risks among staff $[2,29,30]$.

One of the key factors affecting the hand hygiene compliance is constant awareness about the threat and regular monitoring of the hand hygiene procedure. A staff employee should be provided with evidence that he/she is a transmitter of $C$. difficile spores or other multi-drug resistant bacteria, which can be carried out by using microbiological tests, a fluorescent solution and UV light to verify hand disinfection procedures. A quick and effective method of checking the cleanliness of the hands is to use a scanner with built-in UV lamps and a camera. A medical worker applies a preparation containing a special fluorescent marker to his/her hands and places them under the UV lamp. At the same time, the computer monitor displays areas on the hands in appropriate colours indicating contamination, which means that the correct procedure for hand hygiene was not properly followed. The results of such research raise the awareness of the responsibility for human life, increase the willingness to be more involved in thorough hand washing, and strengthen internal motivation [31].

There are several recognized ways to monitor hand hygiene, one of which is to determine the consumption level of a preparation for hand disinfection in individual wards, e.g. per person-day or the number of medical personnel. Direct observation of the implementation of the hand hygiene procedure is also part of monitoring the level of hand hygiene. Regardless of the implemented method of monitoring hand hygiene, proper reporting of the obtained results also plays an important role. Feedback for healthcare professionals - on monitoring the use of hand sanitizers and on follow-up should be an important motivating and educational element in a staff hand hygiene programme [4]. The effectiveness of products for hand hygiene can be demonstrated in laboratory tests following the recommendations of standards, for example CEN: EN 1499 and EN 1500, ASTM E-2276, ASTM E-2613, ASTM E-2011 [32-36].
Many studies show that the mere promotion of hand hygiene, even if lasting several months, has no final effect without simultaneous supervision and development of awareness [31]. The authors of a 2016 study estimated that after one of the promotional campaigns, the hand hygiene compliance rate increased from $49 \%$ to $69 \%$ after one year, but only 3 years later it fell to 58\% [37]. In another study of this type, after the first year of the campaign, the hand hygiene compliance rate increased from $41 \%$ to $58 \%$, but remained at a stable level of $50 \%$ in subsequent years. To meet the challenge, the authors of the study introduced daily supervision and involved epidemiological nurses to remind doctors about the need for hand hygiene. After introducing those changes and after just a 6-month evaluation period, they achieved a high increase in the indicator that reached $83 \%$ [38]. The conclusion drawn was that daily supervision of the implementation of the procedure and raising awareness among the staff had the greatest impact on the increase of the hand hygiene index. Although the result of re-intervention in this study was satisfactory, the fact that it was necessary to constantly remind staff about patient safety and to control the hand washing procedures was a disturbing phenomenon to be observed among educated healthcare personnel.

Another factor affecting hand compliance hygiene is having up-to-date and thorough knowledge about the factors that threaten the stability of processes contributing to patient safety, and a sufficient amount of time to train staff to fight infection. It was demonstrated that only $43 \%$ of nurses had appropriate knowledge of $C$. difficile spores or other pathogens. The study showed that $19 \%$ of the surveyed staff believed that the most important HAI transmission vector was reusable equipment, and $10 \%$ of them indicated disposable equipment to be the culprit. The study also revealed that only $68 \%$ of the nursing staff knew that hand washing protects against cross-infections (the transmission of microorganisms from one patient to another through nondisinfected surfaces and instruments), while $27 \%$ thought that hand washing is used only to prevent air and dust-borne infections [39]. Education and broadening knowledge should go hand-in-hand with proper hand hygiene. Despite a large number of staff members declaring compliance with hygiene procedures ( $72.1 \%$ of nurses, $57.5 \%$ of doctors) as many as $7.5 \%$ of the personnel admitted that quite often they did not comply with hygiene procedures, and almost $30 \%$ said that sometimes they did not comply with certain procedures (mainly doctors). Only 69\% of staff participated in HAI prevention trainings on a regular basis [40]. Another global study reported that only $39 \%$ of medical workers follow hygiene procedures [41]. From this data it can be concluded that there is a need to introduce more mandatory trainings for medical personnel regarding knowledge of the factors that threatens the stability of processes affecting patient safety.

However, complying with the requirements laid down in the $\mathrm{WHO}$ and CDC procedures, i.e. washing hands for 20-30 seconds using an alcohol-based preparation or for 40-60 seconds using soap and water, can be problematic. The medical worker, due to lack of time, irritated hands, or aversion to proper hand hygiene, does not observe the time needed for hand washing. An additional problem is the mere technique of rubbing hands and fingers during washing hands and the use of insufficient amount of cleaning or disinfecting product. One of the studies revealed that $28 \%$ of cases of adverse events, which included HAI, resulted 
from the negligence of medical staff [15]. According to the WHO, the global average for staff compliance with hygiene procedures is only $38.7 \%$, with baseline indicators in developed and developing countries being in the range of $5 \%-89 \%$ [15]. Factors affecting non-compliance with hand hygiene practices by personnel are presented in Table 2.

Table 2. Factors affecting poor hand hygiene compliance by personnel [15]

\begin{tabular}{|c|c|c|}
\hline Technical & Organizational & Personal \\
\hline $\begin{array}{l}\text { Hand washing } \\
\text { detergent } \\
\text { causes irritation } \\
\text { Hand washing } \\
\text { detergent dries } \\
\text { the skin } \\
\text { Wash basins } \\
\text { are located in } \\
\text { inconvenient } \\
\text { places to use } \\
\text { Shortage of } \\
\text { wash basins } \\
\text { Shortage of } \\
\text { soap } \\
\text { Shortage of } \\
\text { disposable } \\
\text { towels }\end{array}$ & $\begin{array}{l}\text { Excess of activities or lack of time } \\
\text { Incorrect practices among } \\
\text { colleagues or superiors } \\
\text { Low level of knowledge, } \\
\text { experience and education, no } \\
\text { knowledge of guidelines } \\
\text { No reward or incentive system } \\
\text { Hand hygiene is not treated as } \\
\text { an institutional priority } \\
\text { No scientific information on the } \\
\text { relationship between improved } \\
\text { hand hygiene and HAI } \\
\text { No active participation in the } \\
\text { promotion of hand hygiene at } \\
\text { institutional level } \\
\text { Unfriendly atmosphere of } \\
\text { institutional security }\end{array}$ & $\begin{array}{l}\text { Low risk of catching } \\
\text { infection from a patient } \\
\text { Sceptical approach to } \\
\text { the importance of hand } \\
\text { hygiene } \\
\text { Patient needs are more } \\
\text { important } \\
\text { Disagreeing with } \\
\text { recommendations } \\
\text { Forgetting about hand } \\
\text { hygiene } \\
\text { Hand hygiene interferes } \\
\text { with the relationship } \\
\text { between patient and } \\
\text { healthcare staff } \\
\text { Conviction that using } \\
\text { gloves eliminates the need } \\
\text { for hand hygiene }\end{array}$ \\
\hline
\end{tabular}

The hands of medical personnel carry the highly pathogenic Clostridium difficile spores [12]. The skin on the hands of medical personnel, in addition to its own natural microbiota, known as permanent flora, acquires, through constant contact with the hospital environment, transient flora, including C. difficile spores. One of the most important methods of protection against this pathogen is rigorously followed hand hygiene procedures [30]. According to the WHO guidelines, the recommended hand hygiene technique for eradicating $C$. difficile spores is the Ayliffe technique, which involves the mechanical removal of the transient flora with running water and soap from the hands of both staff and hospitalized patients with CDI. The duration of hand washing must last 40-60 seconds to ensure that all impurities are removed. The very technique of washing hands for disinfection purposes involves applying soap to wet hands, then spreading the soap and thorough washing, rubbing the interdigital spaces, thumbs and fingertips in a five-fold repetition. Finally, for proper disinfection, the hands should be rinsed thoroughly with running water, the hands dried with a disposable paper towel, turning off the tap with the elbow or using a disposable towel [15]. The WHO recommends the following procedures for hand hygiene [18]: A. Wash hands with soap and water when visibly dirty or visibly soiled with blood or other body fluids, or after using the toilet.

B. If exposure to potential spore-forming pathogens is strongly suspected or proven, including outbreaks of $C$. difficile, hand washing with soap and water is the preferred means.

C. Use an alcohol-based handrub as the preferred means for routine hand antisepsis in all other clinical situations described in items $\mathrm{D}(\mathrm{a})$ to $\mathrm{D}(\mathrm{f})$ listed below, if hands are not visibly soiled. If alcohol-based handrub is not obtainable, wash hands with soap and water.

D. Perform hand hygiene: a) before and after touching the patient;

b) before handling an invasive device for patient care, regardless of whether or not gloves are used;

c) after contact with body fluids or excretions, mucous membranes, non-intact skin, or wound dressings;

d) if moving from a contaminated body site to another body site during care of the same patient;

e) after contact with inanimate surfaces and objects (including medical equipment) in the immediate vicinity of the patient;

f) after removing sterile or non-sterile gloves.

E. Before handling medication or preparing food perform hand hygiene using an alcohol-based handrub or wash hands with either plain or antimicrobial soap and water.

F. Soap and alcohol-based handrub should not be used concomitantly.

According to the WHO recommendations, the following hand hygiene technique should be used [18]:

A. Apply a palmful of alcohol-based handrub and cover all surfaces of the hands. Rub hands until dry. Duration of the entire procedure: $20-30$ seconds.

B. When washing hands with soap and water, wet hands with water and apply the amount of product necessary to cover all surfaces. Rinse hands with water and dry thoroughly with a single-use towel. Use clean, running water whenever possible. Avoid using hot water, as repeated exposure to hot water may increase the risk of dermatitis. Use towel to turn off tap/faucet. Dry hands thoroughly using a method that does not recontaminate hands. Make sure towels are not used multiple times or by multiple people. Duration of the entire procedure: 40-60 seconds.

C. Liquid, bar, leaf or powdered forms of soap are acceptable. When bar soap is used, small bars of soap in racks that facilitate drainage should be used to allow the bars to dry.

The method of hand disinfection is not difficult and does not require special explanations. However, it should be added here that proper hand hygiene should be combined with a disinfection procedure that helps in the reduction of HAI transmission through the 'bare below the elbows' (BBE) strategy. This strategy involves the dress code of medical personnel. Originally from the UK, it was developed due to the growing number of organisms that have become resistant to treatment, such as methicillin-resistant Staphylococcus aureus (MRSA) and C. difficile. The idea behind this strategy is to facilitate effective hand hygiene for personnel to minimize infections. According to the BBE strategy, medical personnel who have contact with the hospitalized patients and the hospital environment are required to strictly follow the rules in order to minimize HAI. BBE strategy involves eliminating jewellery (watches, bracelets, rings) and ties by medical personnel, and additionally involves wearing aprons with short sleeves all year round, as well as elimination of painted and long nails [42].

Implementation of BBE strategy can clearly contribute to minimizing HAI. A study by Škodová et al. demonstrated that only $5 \%(\mathrm{~N}=705)$ of the personnel wearing jewellery performed the hand disinfection procedure correctly [43]. Another study revealed that pathogenic bacteria were isolated statistically more frequently in $86 \%$ of people wearing artificial nails [44]. Artificial nails were recognized as a source of transmission of pathogenic bacteria in several epidemic 
outbreaks $[45,46]$. Weber et al. analyzed the impurities under the fingernails and reported that $C$. difficile spores were isolated after contact with a CDI patient in $43 \%(\mathrm{~N}=35)$ of the examined personnel. Another study that dealt with wearing rings and wedding rings confirmed the presence of C. difficile spores near jewellery in $20 \%$ of staff. The authors noted that wearing jewellery significantly reduced the effectiveness of the disinfection of the hands of medical personnel. BBE strategy concerning the dress code of medical staff has a major impact on the transfer of pathogens from physicians to patients [47]. There is a connection between contamination of the hands of medical staff and clothing. Most of the bacteria grown from the aprons and hands of staff were skin commensals of personnel, i.e. naturally occurring, harmless bacteria that make it difficult for other bacteria, including pathogenic bacteria, to settle and multiply [48].

Hand hygiene constitutes a key measure in limiting the spread of infections. This is a simple activity, but lack of consintency in observing it poses a global problem in the healthcare sector. Compliance with hand hygiene procedures should become a priority for the entire institution, being properly emphasized by heads of departments who have administrative support. Adequate time should be allocated to training healthcare staff about infection control, and some sessions should be devoted to hand hygiene. Medical personnel should have access to a safe and continuously operating source of water supply in all facilities, and access to the necessary equipment for washing their hands. An important role is played by the right amount and availability of wash basins, washing and hand hygiene products, as well as the constant availability of disposable towels. Health-care workers should be provided with effective hand hygiene products that only rarely cause irritation, product dispensers should be available in areas of patient care, and it should be ensured that dispensers are working properly and reliably dispensing the right amount of a product. Product dispensers should operate on a non-contact basis to avoid touching the dispenser with contaminated hands, e.g. dispensers should be activated by elbows or have pumps that can be activated by wrists. Alcohol-based hand sanitizers with optimal antimicrobial efficacy typically contain $75-85 \%$ ethanol, isopropanol or propanol, or a mixture of these. The formulations recommended by the WHO contain either $75 \%$ isopropanol or $80 \%$ ethanol. It is necessary to observe the principle that only one pair of gloves should be used for procedures with one patient. The same gloves cannot be used for the next patient. Educational measures should include informing healthcare professionals on those activities performed on the patient that may result in hand contamination, and on the advantages and disadvantages of the different methods used to clean hands. The actual education begins in medical schools and universities, and this knowledge is consolidated during internships and courses. In addition to medical personnel, patients and their families should also be encouraged to work in partnership to promote hand hygiene practices in healthcare facilities $[15,18]$.

\section{CONCLUSIONS}

The 2018 Chief Sanitary Inspectorate (GIS) reports on the current epidemiological situation of hospitals in Poland show that the most common factor of nosocomial infections was
C. difficile spores, which accounted for $41.52 \%$ of all detected epidemic outbreaks [11]. From the literature on this subject it can be concluded that the main factors contributing to poor hand hygiene compliance are the personal beliefs of medical personnel regarding, e.g., low risk of being infected from the patient, disagreeing with procedures, sceptical approach to the importance of hand hygiene, or a claim that patient needs are more important. Non-compliance with proper hand hygiene contributes to healthcare-associated infections which are the primary cause of death and disease complications [15], the spread of multi-antibiotic-resistant strains, including $C$. difficile spores, and is a factor contributing to the occurrence of epidemic outbreaks [4-6].

Minimizing infections associated with C. difficile and other pathogens is only possible by cyclically providing medical personnel with knowledge about the possible sequelae of HAI, microbial agents, and transmission of multi-resistant pathogens as sources of infection. Staff should be reminded about and trained to perform the proper Ayliffe's hand hygiene technique according to the WHO recommendations $[4,15,18]$.

\section{REFERENCES}

1. Tolera M, Abate D, Dheresa M, Marami D. Bacterial Nosocomial Infections and Antimicrobial Susceptibility Pattern among Patients Admitted at Hiwot Fana Specialized University Hospital, Eastern Ethiopia. Advances in Medicine. 2018; 1-7. https://doi: $10.1155 / 2018 / 2127814$

2. Cichońska M. Professional solutions in the hygiene of the hands of the medical staff, increasing the effectiveness of fighting hospital infections. Zakażenia XXI wieku. 2019; 2(5): 249-252. https://doi: 10.31350/zakazenia/2019/5/Z2019039

3. Łoś I, Dziewulska J. Knowledge of nursing staff concerning Clostridium difficile. Aspekty zdrowia i choroby. 2018; 3(1): 109-132.

4. Miętkiewicz S, Nowaczyk B, Dyk D. The role of hand hygiene in the prevention of surgical site infections. Hygeia Public Health. 2018; 53(3): 247-252.

5. Badurek S, Muszytowski M, Stróżecki P, Manitius J. Clostridium difficile-associated disease in patients with chronic kidney disease. Forum Nefrol. 2016; 9(3): 141-148.

6. Kiersnowska Z, Lemiech-Mirowska E, Ginter-Kramarczyk D, Kruszelnicka I, Michałkiewicz M, Marczak M. Problems of Clostridium difficile infection (CDI) in Polish healthcare units. AAEM. 2020. https:// doi: $10.26444 /$ aaem/119321

7. Denisiewicz B. The role of disinfection and handwashing of medical personnel - hands as a reservoir of microorganisms - the role of medical dispensers in maintaining hand hygiene. Zakażenia XXI wieku. 2018; 1(3): $125-128$

8. Kabała M, Aptekorz M, Martirosian G. The role of hospital environment and the hands of medical staff in the transmission of the Clostridioides (Clostridium) difficile infection. Med Pr. 2019; 70(6): 739-745. https:// doi: $10.13075 / \mathrm{mp} .5893 .00856$

9. Dorodgar S, Hatami H, Yadegarynia D, Arab-Mazar Z. Nosocomial Infections: Multicenter Surveillance of Antimicrobial Resistance in Tehran During 2015-2017. Arch Clin Infect Dis. 2018; 13(5): e64246. https://doi: 10.5812/archcid.64246

10. Czarkowski MP, Cieleba E, Kondej B, Sadłocha A. Infectious diseases and poisonings in Poland in 2018. Warsaw: National Institute of Public Health - National Institute of HygieneDepartment of Epidemiology and Surveillance of Infectious Diseases; 2019. p. 17-19.

11. Pawlik K. Clostridiodes (clostridium) difficile - effective infection control methods. Forum Zakażeń. 2018; 9(4): 221-227. https://doi: 10.15374/FZ2018043

12. Nowacka K, Flitta R, Siminska J, Porzych P, Grzyb S, Hagner W. Hand hygiene for the management of a patient infected with Clostridium difficile in the presence of hospital infections. Journal of Education, Health and Sport. 2017; 7(6): 331-344. http://doi: 10.5281/zenodo.815567

13. The sanitary condition of the country in 2018. Główny Inspektorat Sanitarny. 2019. www.gis.gov.pl (10.04.2020) 
14. McFarland LV, Mulligan ME, Kwok RY, Stamm WE. Nosocomial acquisition of Clostridium difficile infection. N Engl J Med. 1989; 320(4): 204-210. https://doi: 10.1056/NEJM198901263200402

15. World Health Organization. WHO Guidelines on Hand Hygiene in Health Care: a Summary. 2009. WHO Press, World Health Organization, Geneva, Switzerland. https://www.cmj.org.pl/cleancare/higiena-rak-wytyczne-who-draft.pdf (5.05.2020)

16. Goślińska-Kuźniarek O, Karpiński TM. Role of hand hygiene among heathcare personnel. Forum Zakażeń. 2014; 5(2): 79-84.

17. Kampf G, Kramer A. Epidemiologic background of hand hygiene and evaluation of the most important agents for scrubs and rubs. Clin Microbiol Rev. 2004; 17(4): 863-893. https://doi: 10.1128/CMR.17.4.863893.2004

18. WHO Guidelines on Hand Hygiene in Health Care. First Global Patient Safety Challenge Clean Care is Safer Care. 2009. WHO Press, World Health Organization, Geneva, Switzerland. ISBN 9789241597906.

19. Piwowarczyk J. Hand hygiene control - Hygiene control in medical facilities. MediNews Information for Professionals of Epidemiology. 2019; 4(1/2019): 7-9. https://www.medilab.pl/userfiles/file/04_2019_ Medilab_MediNews_nr4_rozkladowki_www.pdf (1.10.2020)

20. Otter JA, Yezli S, Salkeld JAG, French GL. Evidence that contaminated surfaces contribute to the transmission of hospital pathogens and an overview of strategies to address contaminated surfaces in hospital settings. Am J Infect Control. 2013; 41: 6-11. https://doi: 10.1016/j. ajic.2012.12.00

21. Knape L, Hambraeus A, Lytsy B. The adenosine triphosphate method as a quality control tool to assess 'cleanliness' of frequently touched hospital surfaces. J Hosp Infect. 2015; 91(2): 166-170. https://doi: 10.1016/j.jhin.20 15.06.011

22. Barbut F. How to eradicate Clostridium difficile from the environment. J Hosp Infect. 2015; 89(4): 287-295. https:// doi.org/10.1016/j. jhin.2014.12.007

23. Cichońska M, Ciemienga E, Daciąg D, Borek M. The level of knowledge and awareness of medical staff on the subject of hand hygiene. Forum Zakażeń. 2019; 10(4): 227-231. https://doi: 10.15374/FZ2019034

24. Tartari E, Muthukumaran P, Peters A, Allegranzi B, Pittet D. Monitoring your institution: the WHO hand hygiene self-assessment frameworkdis it worth it? Clin Microbiol Infect. 2019; 25: 925-928.

25. Mamos AR, Lipińska D, Orszulak-Michalak DE. Analysis of registered nosocomial infections at the district hospital in the Łódź region 20052015. Polish Review of Health Sciences. 2018; 3(56): 294-300. https:// doi: 10.20883/ppnoz.2018.43

26. Niecwietajewa I, Pracz W, Giemza M, Jakubiak J, Szymańczak M, Marusza W. Hand hygiene microbiological control as an important part of multimodal approach for hai prevention. Zakażenia XXI wieku. 2018; 1(5): 209-215. https://doi: 10.31350/zakazenia/2018/5/Z2018036

27. Shi L-s, Xu C-j, Jia H-b, Chen W, Zhou X-f, Li X-h. Spread of Staphylococcus aureus between medical staff and high-frequency contact surfaces in a large metropolitan hospital. Int J Nurs Sci. 2015; 2(4): 366-370. https://doi: 10.1016/j.ijnss.2015.11.001

28. Bhatt J, Collier S. Reducing Health Care-Associated Infection: Getting Hospitals and Health Systems to Zero. Ann Intern Med. 2019; 171: 81-82. https://doi: 10.7326/M18-3441

29. Szumska E. How to properly prepare the hands of the procedure, that the policy of "anything below the elbow". MediNews. 2018; 3: 12-13. https://www.medilab.pl/userfiles/file/Medinews/06_2018_Medilab_ MediNews_nr3.pdf. (1.10.2020)

30. Khan HA, Baig FK, Mehboob R. Nosocomial infections: Epidemiology, prevention, control and surveillance. Asian Pac J Trop Biomed. 2017; 7(5): 478-482. https://doi: 10.1016/j.apjtb.2017.01.019.
31. Haque M, Sartelli M, McKimm J, Bakar MA. Health care-associated infections - an overview. Infect Drug Resist. 2018; 11: 2321-2333. https:// doi: 10.2147/IDR.S177247

32. European standard EN 1499. Chemical disinfectants and antiseptics. Hygienic hand wash. Test method and requirements. Brussels, European Committee for Standardization, 1997.

33. European standard EN 1500. Chemical disinfectants and antiseptics. Hygienic handrub. Test method and requirements. Brussels, European Committee for Standardization, 1997.

34. ASTM International. Standard test method for determining the bacteria-eliminating effectiveness of hygienic handwash and handrub agents using the finger pads of adult subjects. 2003 (designation: E 2276).

35. ASTM International. Standard test method for determining funguseliminating effectiveness of hygienic handwash and handrub agents using fingerpads of adults. 2008 (designation: E 2613).

36. ASTM International. Standard test method for evaluation of handwashing formulations for virus-eliminating activity using the entire hand. 1999 (designation: E 2011).

37. Potocka P, Rożkiewicz D, Ołdak E. Hand hygiene among healthcare personnel - what else we can do. Forum Zakażeń. 2016; 7(4): 289-293. https://doi: 10.15374/FZ2016050

38. Seto WH, Yuen SW, Cheung CW, Ching PT, Cowling BJ, Pittet D. Hand hygiene promotion and the participation of infection control link nurses: an effective innovation to overcome campaign fatigue. Am J Infect Control. 2013; 41(12): 1281-1283. https://doi: 10.1016/j. ajic.2013.04.011

39. Kosonóg K, Gotlib J. Assessment of nurses' familiarity with the principles of aseptics and antiseptics in selected medical procedures. Nursing Problems. 2010; 18(1): 30-40.

40. Kaier K, Mutters NT, Frank U. Bed occupancy rates and hospitalacquired infections - should beds be kept empty? Clin Microbiol Inf. 2012; 18(10): 941-945. https:// doi: 10.1111/j.1469-0691.2012.03956.x

41. Lambe KA, Lydon S, Caoimhe M, Akke V, Aoife H, Walsh M, O'Connor P. Hand Hygiene Compliance in the ICU: A Systematic Review. Critical Care Medicine. 2019; 47(9): 1251-1257. https://doi: 10.1097/ CCM.0000000000003868

42. Turaga KK, Bhagavatula G. What should doctors wear? BMJ 2008; 337:a938. https://doi.org/10.1136/bmj.a938

43. Škodová M, Urra FG, Benítez AG, Romano MRJ, Oritz AG. Hand hygiene assessment in the workplace using a UV lamp. Am J Infect Control. 2015; 43(12): 1360-1362. https://doi: 10.1016/j.ajic.2015.07.003

44. McNeil SA, Foster CL, Hedderwick SA, Kauffman CA. Effect of hand cleansing with antimicrobial soap or alcohol-based gel on microbial colonization of artificial fingernails worn by health care workers. Clin Infect Dis. 2001; 32(3): 367-372. https://doi: 10.1086/318488

45. Moolenaar RL, Crutcher JM, San Joaquin VH, Sewell LV, Hutwagner LC, Carson LA, Robison DA, Smithee LM, Jarvis WR. A prolonged outbreak of Pseudomonas aeruginosa in a neonatal intensive care unit: did staff fingernails play a role in disease transmission? Infect Control Hosp Epidemiol. 2000; 21(2): 80-85. https://doi: 10.1086/501739

46. Gupta A, Della-Latta P, Todd B, Gabriel PS, Haas J, Wu F, Rubenstein D, Saiman L. Outbreak of extended spectrum beta-lactamase-producing Klebsiella pneumoniae in a neonatal intensive care unit linked to artificial nails. Infect Control Hosp Epidemiol. 2004; 25(3): 210-215. https://doi: $10.1086 / 502380$

47. Weber RL, Khan PD, Fader RC, Weber RA. Prospective study on the effect of shirt sleeves and ties on the transmission of bacteria to patients. J Hosp Infect. 2012; 80(3): 252-254. https://doi: 10.1016/j. jhin.2011.12.012

48. Khan R, Petersen FC, Shekhar S. Commensal Bacteria: An Emerging Player in Defense Against Respiratory Pathogens. Front Immunol. 2019; 10, 1203. https://doi.org/10.3389/fimmu.2019.01203 